\title{
ISSUES FOR WOMEN'S LEADERSHIP PATHWAYS IN LARGE ORGANISATIONS
}

\author{
Maria Williamson and Ruth Wilkie
}

Ministry for Women

\begin{abstract}
This paper proposes that work cultural changes are needed to increase opportunities for women to achieve at the highest level, and stop them from dropping out of the 'leadership pipeline'. The research identifies three barriers to women continuing to advance their careers at the same rate as men. These barriers have been identified as:

- unconscious bias against women taking up leadership roles - this can affect recruitment, assessment and development practices (both formal and informal) at every level within an organisation, and can make it more difficult for women to progress into senior leadership roles.

- employer attitudes to breaks in employment (for example, for child-rearing), or a nontraditional career path (for example, community leadership or executive roles), can make it difficult for women to re-enter the mainstream workforce and to maintain an upward career trajectory.

- lack of options for flexible work, or workplace culture which applies informal or formal penalties for using flexible work options, mean that women can stop progressing in their career, or leave the workforce altogether.
\end{abstract}

The evidence behind this analysis, and the solutions available including actions that have the most impact, are set out in two reports published by the Ministry of Women's Affairs: Realising the opportunity: addressing New Zealand's leadership pipeline by attracting and retaining talented women (2013); and Inspiring Action: action plans and research to help you attract and retain talented women (2014).

Disclaimer: The views, opinions and conclusions expressed in this paper are intended to inform and stimulate wider debate. They do not represent government policy.

\section{Introduction}

The 'leaking pipeline' is not what was expected, when women started coming out of education in higher numbers in the 80's, and feminism seemed to have won all its battles. Women are not in leadership roles at the same rate they are in the workforce. We are not making the most of New Zealand's talent, given that women, at 51 percent of the population, 60 percent of New Zealand's domestic university graduates in 2013, and with an employment rate of 59.7 percent (HLFS, Sept 2014), represent a significant pool of talent. 
Women are currently under-represented in leadership roles in New Zealand. Women's participation in leadership is low in the private sector, low in some areas of the public sector, high in the community sector (in management, but not necessarily in governance) (Heathrose, 2013), and unknown in the Māori sector (due to a lack of data).

Research undertaken by the Ministry of Women's Affairs in 2013 identified three major reasons why women 'drop out' of the leadership pipeline: These are: unconscious bias; career breaks; and lack of flexible work options.

Unconscious bias is based on stereotypical views about gender and leadership. Undetected unconscious bias may make it more difficult for women to progress into senior roles and it can be an invisible barrier to career progression particularly in a male dominated organisation (Bailey \& Rosati, 2013; Edwards, Burmester, Evans, Halupka, \& May, 2013).

Women face challenges to the progression of their leadership careers when re-entering the workforce after taking career breaks to provide primary caregiving for children or elderly parents. Employer attitudes to breaks in traditional employment pathways can also make it difficult for women to re-enter the workforce and to maintain an upward career trajectory (Kronos, 2013). Given the increasing skill and leadership talent shortages, supporting highly skilled, qualified women to fully utilise their skills would represent a good return on the investment made in their education and career development.

Lack of options for flexible work, or informal or formal penalties for using flexible work options, can mean that women trade down their skills to gain flexibility. Where flexible work arrangements are available there are often negative consequences, such as women not being offered the challenging roles they need to progress their careers. This can mean that women's careers stagnate, and/or they leave the workforce altogether.

This paper will reflect on the evidence behind this analysis, and the solutions available. It will explore in more details the leaking leadership pipeline, the underpinnings of unconscious bias and what some organisations are doing to eliminate it. It will also consider some myths and the realities about women and the barriers they face to achieve their leadership potential.

Not only are solutions to these issues important for women, their families and communities, but they are also important for New Zealand's international reputation as a leader in gender balance and equity.

\section{Business Case for gender balance in leadership}

International research by Catalyst (2004) and McKinsey \& Company, (2010) found that women in leadership roles bring a diversity of skills and experiences to the decision making table. More diversity in the type of people involved in leadership is often used as a proxy for more diversity of thought in leadership. Greater numbers of women in leadership roles bring more diverse skills and experiences to the decision-making table.

There is compelling international evidence that gender balance in governance and leadership roles correlates with better decision-making, organisational resilience and performance (MWA, 2013). McKinsey \& Company (2010) found that the companies that had more women in senior 
leadership had improved performance which provided them with a competitive advantage. Women provided diversity of decision-making. They focus on different things - and have a different approach to risk.

There is also a strong case for women being present in leadership at the same rate they are present in the population. Having more women in leadership roles not only benefits women but also delivers economic and productivity gains for New Zealand.

As women make 80 percent of consumer decisions on purchases worldwide, they are the dominant drivers of global economic growth. In governance and leadership, women can bring strong connections with customers, stakeholders and investors.

\section{The 'leaking' leadership pipeline}

Research here and internationally shows that at every successive management level, significant proportions of talented women drop out or stagnate below senior management and top leadership positions. This is the leaking pipeline (Desvaux, Devillard, Sancier-Sultan, 2010). It appears that the underlying causes for the leaking pipeline are complex and no single solution will be sufficient.

While women, employers and society make significant investment in developing women's leadership skills and expertise, women will trade down their skills and take a lesser paid job to gain flexibility for themselves and their families. This trade-off means that women are not fully utilising their qualifications, skills or leadership talents.

Research was undertaken in Canada in 1997 and again in 201, with chief executives and women in senior management, to understand why there were low numbers of women at top levels. Different reasons were given for the lack of women coming through; with the chief executives suggesting it was lack of 'line management' experience while senior women referred to the 'inhospitable working environments' (Wohlbold, and Chenier, 2011). The numbers of women entering the talent pipeline had increased somewhat but they were not flowing through to senior management levels in large numbers.

Internationally as well in New Zealand, some of the reasons for women's lack of progress are attributed to the different educational choices made by men and women. It appears that this is a problem because many organisations choose senior employees from those working in technical disciplines. The choices women make in terms of their studies (such as business, management, and public administration rather than engineering and related technologies) may be limiting women's opportunities for career advancement (Wohlbold \& Chentier, 2011).

Not only do women choose different career disciplines from men, they also experience different patterns of employment compared to men. Two researchers - Alice Eagly and Linda Carli (2007) offer a new metaphor - the labyrinth - to describe the numerous and varied barriers that confront women from the earliest stages of their careers. "The Labyrinth refers to "the numerous and varied barriers - some obvious, some subtle - that confront women from the earliest stages of their careers" (Eagly \& Carti, 2007). Eagly and Carti (2007) identified conflicting gender and leadership expectations, family responsibilities, and discomfort with self- 
promotion as some of the barriers women experience at the same time they are developing their careers.

\section{Unconscious bias}

Research shows that much of the perceptions of gender and leadership stereotypes is unconscious and leads to unconscious bias in decision making about recruitment, development, performance, reward and recognition in leadership roles (MWA, 2013, 2014).

Unconscious bias comes from a person's unconscious knowledge (what we know) and unconscious thinking processes (how we think). Unconscious bias is often embedded in the culture of the organisation and can influence organisational decisions about recruitment, assessment and the career development practices (both formal and informal) of women leaders (MWA, 2013).

When stereotypical beliefs are widely shared they gain more credibility making individuals more likely to apply them in making judgments. They can narrow the range of effective leadership behaviours and styles in the workplace. In the absence of firsthand experience on which to base judgments, or training to minimize bias, individuals fall back on perceptions that may result from stereotypes.

It is also clear that unconscious bias has a role to play in reducing women's opportunities to reach senior leadership roles. Women are often judged differently from men. When they display the same behavior as men they can be criticised as being too aggressive, or they may be considered too passive and this results in the perception that they lack confidence and need to do something about this.

While men may be treated as individuals often women are treated as representative of their gender with the consequences that long held stereotypes about women can mean they are not considered 'right' for a particular position and they may be seen as a 'greater' risk than men. Men are often considered for roles on their perceived potential whereas women are judged on their past experience.

\section{Myths and Realities}

Research shows that unconscious bias underlies many of the myths about women and their leadership aspirations. Five myths in particular create barriers for women's leadership aspirations and are underpinned by unconscious bias assumptions about women's working lives. The reality is somewhat different from the myths (KPMG LLP, YSC, 30\% Club, 2014).

The business case for gender diversity is working and women are coming up the ranks (KMPG et al 2014).

As discussed in an earlier section of this paper it is assumed that the business case stands on its own. The expectation is that businesses will heed the evidence and make rational decisions to increase the numbers of senior women on their boards and executive to benefit from the positive performance opportunities this will bring to the organisation. The reality is that this is 
not happening and it is only when the head of an organisation - chief executive or chairperson makes a personal commitment to improving gender balance that change is more likely to happen.

Top level commitment is critical to driving change. In New Zealand this has been demonstrated by company leaders expressing their personal values about making gender balance happen, for example, the Bank of New Zealand (BNZ, 2014). In the report Diversity delivers a distinct competitive advantage the BNZ CEO states "the experiences of women and men at BNZ were different and the age-old argument or excuse that women were not progressing owing to their 'family role' was no longer feasible" (BNZ, 2014).

The BNZ executive team considered that "achieving gender equity in New Zealand will deliver significant gains to our nation - women are guarantors of growth and an economic force not to be ignored" (BNZ, 2014). To make this happen the executive committee agreed a strategy to ensure equal opportunity for all its women employees starting with gender equity within their organisation as the strategic objective.

Starting with a review of the situation for women employees was important so that insight could be gained into the barriers that might be preventing a more balanced gender diversity picture at senior levels. Overcoming these barriers required eliminating unconscious bias in all policies and procedures which affected how women progress their careers. This took personal commitment and accountability at all levels within the organisation so that the talent pipeline of women in middle-level management was identified and strengthened with unconscious bias training so that barriers could be identified and removed (BNZ, 2014).

Women don't aspire to leadership roles (KMPG et al 2014).

This myth asserts that women don't reach the top levels of leadership because they are not interested in doing so. The research found that in fact 'women's career aspirations do not differ from men's and their ambition grows as their professional experience grows' (KMPG et al 2014). Men and women have similar levels of ambition although women tend to have different definitions of success.

However, unconscious bias has a role to play here. Some of the prejudice against women leaders flows from the incongruity that people often perceive between the characteristics typical of women and the requirements of a leader role. Discrimination against women leaders occurs because many people consider that women have less leadership ability than men.

Women can be criticised as being too aggressive when they display the same behaviour as men. They may also be considered too passive and the perception can be that they lack confidence. But there is no empirical evidence suggesting that there is a meaningful difference in the way men or women lead in terms of outcomes or effectiveness (Jonsen, Maznevski \& Schneider, 2010).

Women don't get to the top because they lack confidence (KMPG et al 2014).

It is also clear that unconscious bias has a role to play in reducing women's opportunities to reach senior leadership roles. Women are often judged differently to men. Men may be 
considered for roles on their perceived potential whereas women are judged on their past experiences. Recent research on performance reviews in the IT industry showed that women were criticised for their personality traits far more than men (Synder, 2014).

Women often do not receive the coaching they need to help them understand the company's culture and learn the business. They may find it difficult to find a sponsor, (a senior leader who can promote them within the company) because senior men may consider it difficult to build their relationship with a woman in the same way they would a man. Lacking a sponsor can be a key barrier to women getting leadership opportunities.

Women's confidence is often inferred from their interpersonal style and confused with their alertness to risk. The reality is that women have confidence in themselves, are clear about their abilities and see no advantage in overselling themselves (KMPG et al. 2014).

Women lack the leadership qualities needed at the top (KMPG et al. 2014).

As discussed earlier in this paper stereotyping can make it difficult for women to gain access to leader roles, and can produce conflicting expectations concerning how female leaders should behave - that is, people expect men to be - assertive, dominant, and authoritative, taking charge and women to be - warm supportive, kind and helpful taking care (Catalyst, 2007).

Even when an individual women actually has the qualities thought necessary for leadership, people may believe that she does not 'have what it takes' for success as a leader merely on the basis of her gender. 'Think leader, think male' is a reminder of the biases that link leadership and masculinity. The reality is that the majority of men and women's leadership behaviour is the same. But gender stereotyping clearly influences how these behaviours are perceived (Whelan, 2012).

Children stop women from getting to the top (KPMG, 2014).

In reflecting on the myth above while caregiving can reduce women's commitment to a career, in reality while it may slow women's career progress it has not been found to be significant in stopping them getting to the top (KMPG, 2014). Surveys of women in their 20s and 30s, and men, indicate they see personal and family responsibilities as the primary barriers to women's career success (Sanders, Hrdlicka, Hellicar, Cottrell \& Knox, 2011).

For example, some Australian organisations will not consider candidates for senior roles, if there has been a career break or some experience has been in a part-time work role. Research by Kronos (2013) found that Australian employers are predisposed "toward an 'ideal worker' profile; one that is young, male, and unattached". This can mean that organisations are at risk of missing out on 'hidden' local talents, and the opportunities to build loyalty, a diverse culture, and boost productivity. (Kronos, 2013).

A central issue for organisations wanting to attract and retain talented women back into the workforce is how current recruitment, development and promotion practices allow for women's career breaks and /or non-traditional career paths. A US study showed that most women were eager to get help with re-training so they can return to work after a career break (Hewlett, Luce, 2005). 
However the 'pull' factors of family responsibility can be intensified by 'push' factors - features about the job or workplace that encourage women to leave, such as, lack of meaningful work, under-stimulation and lack of responsibility (Cabrera, 2009).

The second barrier identified in the research (MWA, 2013), is the impact of career breaks and re-entry to work and the career pipeline. Again, some of these barriers come from unconscious bias, but many of them can be quite practically addressed

\section{Flexible working arrangements and career breaks}

Policies such as paid parental leave and flexible work provisions enable women (and male caregivers) to make choices about how they balance their work and caregiving responsibilities. These policies also assist women to stay engaged with their workplace and enable employers to continue to benefit from their skills and experience.

A global survey indicated that, although 80 percent of employees would like to have more flexible working options, people would only use them if there were no negative consequences at work (PwC, 2009).

There is a difference between working flexibly and working part-time. Part-time might be one form of flexibility, but flexible work also includes working outside core work hours, outside the office, or other arrangements. And it is not just women who want to work flexibly, men also want to be able to be more involved in their children's lives.

Despite that, there is evidence that women working part-time may get stuck in such a role for the rest of their careers because the organisation does not see this as a short-term option that workers can use before resuming their full-time careers (Guillaume, \& Pochic, 2009; Paynton \& Rolland, 2013). Lack of visibility when women work part-time can negatively affect their career progression and there is also a belief that flexibility is not possible in leadership roles. Organisations also do not appear to recognise the experience women gain while working parttime or what they achieve during that time.

So what can good organisations do to address barriers to flexible work and unconventional career paths? There are some strategies that companies can use to make the most of their talent pool of skilled women.

Career-enhancing work needs to be interesting, 'high impact' work, that can readily be broken down in such a way that it can be done part-time or flexibly (Hewlett \& Luce, 2005). For example, research on the effects of flexible work and return to work in an accountancy firm showed that where a company is willing it is possible to provide women with the flexibility they need to manage their work and family commitments, as well as keeping clients happy. Some of the change was managed by educating clients to accept a different way of working (MWA, 2010).

Firms that adopt flexible work practices as core to their working arrangements experience bottom line benefits such as lower turnover rates, loyal staff, and lower costs of training. Continuity of service can provide organisations with a business advantage. The use of 
technology also allows staff to work anywhere at times to suit. Leadership plays a key part in the way flexibility is perceived.

\section{Conclusion}

The question I have attempted to answer in this paper is whether workplace practices consciously or unconsciously count against women in leadership roles. The research shows that there is much to be done to ensure that we make the most of our highly educated talented women. In New Zealand as in many other countries, female graduates now outnumber male graduates but the qualifications they achieve may not be in areas of expertise that provide the best career pathway for women. It is not just the qualification that is important it is also the type of work experiences that the person is offered which may or may not provide career opportunities which can realise leadership ambitions.

Unconscious bias clearly undermines women's career pathways to leadership roles, and nontraditional career pathways result in women receiving fewer leadership opportunities. It is also clear that unconscious bias plays a significant role in making it more difficult for women to progress their careers particularly when they take time out for caregiving.

Firms that make flexible work practices available to all staff where possible, making it the norm within the workplace, are likely to see an increase in staff retention as well as increased productivity. Flexible workers should also receive the same career opportunities as other workers. While many women may require some flexibility while raising their children this is likely to be for a relatively short period of time given the evidence that highly skilled women do want to advance their careers. Firms that continue to maintain links to those on parental leave are much more likely to retain their highly skilled female staff when they are ready to return to the workplace.

Organisations that want to make the most of their female workforce need to consider what strategies they have in place to prevent unconscious bias from occurring at all levels of management. Making managers accountable for improving gender balance at all levels is one strategy that has been found to work.

Combating the challenge of the 'leaking pipeline' of highly qualified skilled women from the New Zealand economy by ensuring that there is increased gender balance at all management levels and that flexibility is available when needed has been shown to result in improved firm performance and productivity.

Future research could include an evaluation of the implementation and take-up of the extension of flexible work to all workers with employers and employees. Reviewing whether flexible work has been normalised into New Zealand employment culture, and whether New Zealand women's career pathways have improved over time, will be important to understanding what progress women are making with their careers through the management pipeline into leadership roles.

Further information on strategies, tools and actions to assist organisations to increase gender diversity as well as combatting unconscious bias, are available on the Ministry for Women's website in the 'Inspiring Action' searchable database and the corresponding publication. 


\section{References:}

Bailey, A., and Rosati, C. (2013). The Balancing Act: a study of how to balance the talent pipeline in business. London: Harvey Nash: Cited in MWA (2013) Realising the opportunity: Addressing New Zealand's leadership pipeline by attracting and retaining talented women. http://mwa.govt.nz/documents/realising-opportunity-addressing-newzealand\%E2\%80\%99s-leadership-pipeline-2013

Bank of New Zealand. (2014). Diversity delivers a distinct competitive advantage: Diversity case study. New Zealand: Bank of New Zealand.

Cabrera, E.F. (2009). 'Fixing the leaky pipeline: five ways to retain female talent', People and Strategy, 32(1), 40-45.

Catalyst. (2004). The bottom line: Connecting corporate performance and gender diversity. New York: Catalyst.

Catalyst. (2007). The Double-bind Dilemma for Women in Leadership: damned if you do, damned if you don't. New York: Catalyst. Retrieved from

http://www.catalyst.org/knowledge/double-bind-dilemma-women-leadership-damned-if-youdo-doomed-if-you-dont

Eagly, A., and Carli, L.I. (2007). Through the Labyrinth: The Truth about how women become leaders. Boston. Harvard Business School Press.

Edwards, M., Burmester, B., Evans, M., Halupka, M., and May, D. (2013). Not Yet 50/50: barriers to progress of senior women in the Australian Public Service. ANZSOG Institute for Governance. Canberra: University of Canberra.

Guillaume, C., and Pochic, S. (2009). 'What would you sacrifice? Access to top management and work-life balance', Gender, Work and Organization, 16(1), 14-36. Doi:10.1111/j.14680432.2007.00354.x

Heathrose, Research Ltd. (2013). Te Mana Tu o te Wahine: Women as Leaders in the Community and Voluntary Sector. Women in Leadership Aotearoa (WILA).

Hewlett, S..A., and Luce, C.B. (March, 2005). 'Off-Ramps and on-ramps: keeping talented women on the road to success', Harvard Business Review,.

Jonsen, K., Maznevski, M.L., and Schneider, S.C. (2010). 'Gender differences in leadership believing is seeing: implications for managing diversity' Equality, Diversity and Inclusion: An International Journal: cited in Realising the Opportunity: Addressing New Zealand's leadership pipeline by attracting and retaining talented women. Wellington: Ministry of Women's Affairs.

KPMG, YSC, 30\% Club. (2014). Cracking the Code. UK: KMPG LLP. Retrieved from http://www.kpmg.com/UK/en/IssuesAndInsights/ArticlesPublications/Documents/PDF/Abou t/Cracking\%20the $\% 20$ code.pdf 
Kronos. (2013). Australian Employers Fixated on 'Ideal Worker' Profile. Sydney: Kronos. Retrieved from http://www.kronos.com.au/pr/australian-employers-fixated-on-idealworker-profile.aspx

McKinsey \& Company (2010). Women Matter 2010: Women at the top of corporations: Making it happen. New York: McKinsey \& Company.

Ministry of Women's Affairs. (2014). Inspiring Action: action plans and research to help you attract and retain talented women. http://mwa.govt.nz/sites/public files/MWA bibliography\%20complete\%20\%28large\%29.p $\underline{d f}$

Ministry of Women's Affairs. (2013). Realising the opportunity: Addressing New Zealand's leadership pipeline by attracting and retaining talented women. Wellington. http://mwa.govt.nz/documents/realising-opportunity-addressing-newzealand\%E2\%80\%99s-leadership-pipeline-2013

Ministry of Women's Affairs. (unpublished 2011). The Business Case for Women on Corporate Boards: A Selective Review of the Evidence. Ministry of Women's Affairs, Wellington.

Ministry of Women's Affairs. (2010). Workplace Flexibility in the Accounting Sector. Wellington: MWA.

Poynton, A., and Rolland, L. (2013). Untapped Opportunity: the role of women in unlocking Australia's productivity potential. Australia: Ernst \& Young. Retrieved from

http://www.ey.com/Publication/vwLUAssets/Untapped opportunity -

The role of women in unlocking Australias productivity potential/\$FILE/EY-

Untapped-opportunity-The-role-of-women-in-unlocking-Australias-productivitypotential.pdf

PwC. (2009). Meeting tomorrow's workforce needs* Flexible work arrangements. Boston: PricewaterhouseCoopers. Retrieved from http://www.pwc.com/en US/us/peoplemanagement/assets/flexible-workforce-arrangements.pdf

Sanders, M., Hrdlicka, J., Hellicar, M., Cottrell, d., and Knox, J. (2011). What stops Women from Reaching the Top? Bain and Company. Retrieved from

http://www.bain.com/Images/BAIN BRIEF What stops women from reaching the top.pdf

Synder, K. (August, 2014). The abrasiveness trap: High achieving men and women are described differently in reviews. Fortune. Retrieved from

http://fortune.com/2014/08/26/performance-review-gender-bias/

Whelan, J. (2012). 'The barriers to equality of opportunity in the workforce: the role of unconscious bias'. In Women in Leadership: understanding the gender gap. Melbourne: Committee for Economic Development of Australia. Retrieved from http://www.ceda.com.au/media/310731/cedawiljune\%202013final.pdf

Wohlbold, E., and Chentier, L. (2011). Women in Senior Management: Where are they? The Conference Board of Canada. 